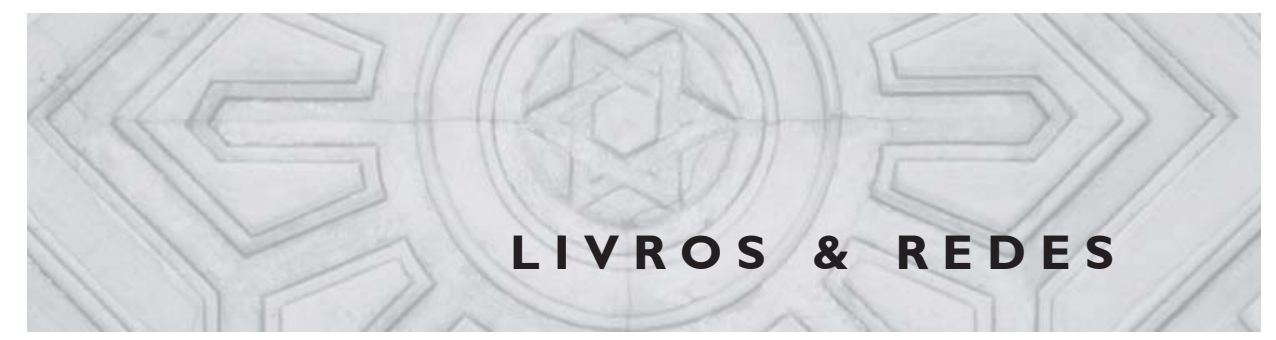

\title{
A milícia da Inquisição: familiares do Santo Ofício no Brasil colonial
}

\author{
The militia of the Inquisition: members of the Holy \\ Office in colonial Brazil
}

\author{
Georgina Silva dos Santos \\ Rua Professor Ortiz Monteiro, 296/303 \\ 22245-100 Rio de Janeiro - RJ - Brasil \\ georginasantos@uol.com.br
}

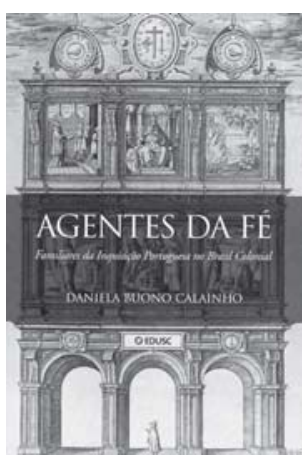

Calainho, Daniela Buono.

Agentes da fé: familiares da Inquisição portuguesa no Brasil Colonial. Bauru: Edusc, 2006. 208p.

\begin{abstract}
A Inquisição portuguesa condenou crenças estranhas à Igreja e con dutas adversas à moral católica, no Reino e nos domínios do império ultramarino, durante três séculos. Instaurada em Portugal em 1536, por solicitação régia, condenou heresias perseguindo e processando apóstatas, feiticeiras, sodomitas, bígamos, mouriscos e, sobretudo, cristãos-novos. Os réus, julgados e sentenciados conforme a gravidade dos delitos, enfrentaram o degredo, a dureza das galés, a humilhação dos açoites públicos e dos hábitos penitenciais quando escaparam da pena capital, a fogueira.
\end{abstract}

Ao contrário de Goa, única possessão portuguesa no ultramar a contar com um tribunal inquisitorial desde 1560, o Brasil não foi sede do Santo Ofício. Esteve todo o tempo subordinado ao tribunal de Lisboa. Mas a Inquisição estendeu seus tentáculos até a América portuguesa, realizando, ao longo dos séculos XVI, XVII e XVIII, três Visitações. O saldo dessas inquirições presididas por inquisidores, enviados diretamente da capital do Reino, foi matéria de estudo por parte de historiadores brasileiros que, recorrendo às fontes inquisitoriais, analisaram a estrutura do tribunal, as relações entre a Inquisição e o clero local e o nível de sociabilidade dos cristãos-novos na colônia (Salvador, 1969; Novinsky, 1972; Siqueira, 1978) desbravaram esse campo de investigação, alargado uma década adiante com as indagações promovidas pela Nova História Francesa. Os clássicos O diabo e a Terra de Santa Cruz, de Laura de Mello e Souza (1986) e Trópico dos pecados, de Ronaldo Vainfas (1989), reconstituíram o universo religioso e moral do Brasil de antanho, a vida sexual dos colonos, suas ousadias e desgraças, retirando da penumbra a trajetória de homens e mulheres anônimos, enredados nas teias do Santo Ofício. Lana Lage da Gama Lima (1990) e Luiz Mott (1993) deram contribuições decisivas à historiografia do período colonial, investigando as desditas dos padres solicitantes, místicas, fanchonos e calunduzeiros do Brasil colonial.

O livro de Daniela Buono Calainho, Agentes da fé: familiares da Inquisição portuguesa no Brasil Colonial, insere-se nessa corrente, 
embora venha a público 15 anos depois de sua elaboração e após a tese de doutoramento da autora (Calainho, 2000). Apresentado como dissertação de mestrado na Universidade Federal do Rio de Janeiro em 1992, com o título Em nome do Santo Ofício: familiares da Inquisição portuguesa no Brasil Colonial, impôs-se logo como referência para os estudiosos do Santo Ofício, no Brasil e em Portugal, e conserva ainda hoje a mesma importância. Ao tratar dos homens que atuaram na milícia inquisitorial, apreendendo suspeitos de heresia e conduzindo-os ao tribunal, Calainho deteve-se sobre tema inexplorado pelos historiadores brasileiros e fontes até então pouco freqüentadas pelos estudiosos da Inquisição portuguesa: as habilitações para o cargo de familiar.

Ancorado em excelente pesquisa documental e erudição bibliográfica, Agentes da fé é composto de três capítulos. O primeiro explica a formação desse grupo de oficiais da Inquisição, cuja origem confundese com o nascimento da instituição em Portugal e na Espanha. Analisa os requisitos exigidos para o cargo de familiar e as regalias concedidas aos habilitados, à luz dos critérios de classificação que edificaram as sociedades estamentais ibéricas: a honra e o privilégio. O modelo hierárquico português, patenteado nas Ordenações do Reino, é ponto de partida para uma reflexão arguta sobre o mito da pureza de sangue, cerne da ideologia racista responsável pelo estigma de cristãos-novos, indígenas, negros e mulatos na sociedade colonial.

As restrições jurídicas ao ingresso dessas minorias e seus descendentes nos quadros inquisitoriais foi regra geral. A remuneração oferecida pelo tribunal aos familiares dependia de cada prisão realizada, logo era imperativo que os candidatos tivessem algum meio de sobrevivência. Os postulantes ao cargo submetiam o passado de sua parentela, até a terceira geração, às averiguações dos comissários da Inquisição. Apenas os limpos de sangue, isto é, sem parentesco com "gente de nação" e demais "raças infectas" poderiam ser "encarregados de negócios de segredo e importância", representando o tribunal.

$\mathrm{O}$ alto custo das provas genealógicas cabia aos candidatos, mas Calainho demonstra como os privilégios concedidos aos familiares constituíram um grande atrativo para os habilitandos. Segundo a autora, em 1562 o monarca d. Sebastião dispensou-os do pagamento de fintas, talhas, pedidos e empréstimos, e protegeu seus bens móveis e imóveis de confisco. Em sinal exterior de distinção e prestígio, permitiulhes portar espadas, punhais ou adagas, até mesmo nas prisões que efetuavam. Autorizou, ainda, que suas mulheres e seus filhos pudessem trazer em suas roupas a seda usada somente por pessoas que possuíam cavalos. Em 1580, no reinado de d. Henrique, os familiares adquiriram o direito de foro privativo. Nas causas-crime, fossem autores ou réus, seus juízes seriam os inquisidores, exceto nos crimes de lesamajestade, como motins, revoltas ou violação de correspondência real, e nos casos de incêndios dolosos, roubos, arrombamentos e crime nefando contra-natura, ou ainda se delinqüissem à frente de algum ofício público.

O número de familiares no Brasil colonial foi significativo. Com base em levantamento documental de fôlego, a historiadora quantificou os processos de habilitação (familiaturas) relativos à Colônia entre os 
séculos XVII e XIX. No capítulo 2 apresenta a análise dos dados coligidos com o auxílio de gráficos e tabelas bem concebidos. Nos 25 volumes que integram os Livros de Habilitações do Santo Ofício, organizado pela equipe de arquivistas da Torre do Tombo, em Lisboa, Calainho localizou 1.708 familiares. Nesse universo, 101 cartas foram expedidas no século XVII, 1.546 na centúria seguinte e 61 até o ano de 1821, data da extinção do tribunal em Portugal.

A amostragem permitiu à autora demonstrar com segurança a concentração geográfica e temporal desses 'agentes da fé' na colônia, retificando impressões equivocadas. Em termos gerais, a concessão de cartas de familiar seguiu "fielmente o rastro do desenvolvimento econômico das Capitanias" e sua importância político-administrativa. As mais prósperas no Seiscentos, Bahia e Pernambuco, contavam com mais de $60 \%$ dos familiares da colônia, contrastando com os $10 \%$ residentes no Rio de Janeiro e com a inexpressividade das outras regiões. A dinamização dos circuitos mercantis na segunda metade do século XVIII, relacionada à empresa aurífera, estimulou o número de candidaturas na região das Minas e do Rio de Janeiro, ampliando a atuação do braço inquisitorial nessas áreas.

A análise dos números ficaria incompleta caso Calainho desprezasse as trajetórias individuais de alguns familiares, sem explorar todo o potencial das familiaturas. As habilitações para o cargo de familiar reúnem dados sobre o local de nascimento e a morada do sujeito, o histórico de seus ancestrais e do cônjuge feminino, sua fonte de renda ou seu ofício e o círculo de relações sociais que construiu. Calainho demonstra que a imensa maioria dos familiares na colônia estava ligada ao comércio, fossem eles proprietários de modestos armazéns e lojistas ou mercadores de grosso trato, vinculados a exportação de açúcar e outros produtos ou traficantes de escravos. Verificável no século XVII, essa tendência se acentuou nos séculos XVIII e XIX, atingindo patamares de $50 \%$ e $64 \%$ cento dos indivíduos habilitados com profissão declarada, respectivamente.

A possibilidade de amenizar o peso do fisco régio, do exclusivo mercantil, o privilégio do porte de armas durante os deslocamentos impostos pelo ofício e a rivalidade com comerciantes cristãos-novos encorajaram, segundo a historiadora, a entrada dos comerciantes na milícia inquisitorial. Inspirada em Anita Novinsky, Calainho sugere que o Santo Ofício privilegiou agentes com essa mobilidade espacial, porque as viagens entre as capitanias para a compra e venda de produtos facultavam aos comerciantes o contato com gente de costumes e crenças diversas, particularmente negociantes de origem judaica. A projeção econômica e política dos cristãos-novos e a competição nos negócios de exportação instigaram os comerciantes cristãos-velhos a enfrentar os concorrentes, evocando o prestígio dos estatutos de limpeza de sangue e o poder conferido aos familiares.

As motivações para o alistamento no corpo de familiares da Inquisição excediam muitas vezes o "desejo de servir ao reto ministério do Santo Ofício". Houve, é verdade, aqueles que abraçaram com fervor a tarefa de auxiliar o tribunal a capturar hereges para emendá-los e reintegrá-los ao seio da Santa Madre Igreja, como o governador da 
Bahia, Antônio Telles da Silva, "um dos mais zelosos e eficientes familiares que a colônia conheceu". Mas alguns abusaram das prerrogativas do posto e outros tantos se fizeram passar por familiares da Inquisição sem nomeação. Esse é o mote do terceiro e último capítulo de Agentes da fé, no qual Calainho revela as contradições do sistema perverso de delação incitado pela Inquisição.

Embora espionassem, prendessem e investigassem suspeitos, cumprindo as diligências ordenadas pelo tribunal, os familiares não eram os principais responsáveis pelas denúncias. A documentação das Visitações realizadas na colônia atesta que a própria população, apavorada com a chegada do inquisidor, delatava vizinhos, parentes e sócios no 'tempo da graça', período em que as culpas ficavam isentas de penas corporais e confiscos. A pedagogia do medo, utilizada pelo Santo Ofício para intimidar desvios religiosos e morais, serviu com eficácia aos propósitos do tribunal, mas permitiu às avessas que atentassem contra sua autoridade.

De passagem por Pernambuco, Januário de São Pedro, processado pelo Santo Ofício em 1740 por fingir-se de padre e familiar, vendeu supostas indulgências a um rico senhor de engenho, recebendo em troca esmola considerável e o hábito de familiar do falecido pai do proprietário. Entre outros desatinos, o embusteiro prendeu, em nome do tribunal, um fazendeiro que, segundo o vulgo, tinha o costume de açoitar uma imagem de Nossa Senhora. Ordenou que fizessem um inventário de seus bens e se apossou de sua riqueza. O roubo e a rapina campeavam também entre os familiares nomeados pela Inquisição. Conta-nos Calainho que João Garcia subtraiu duas pistolas do cristão-novo David Mendes da Silva, preso em Minas no ano de 1730, alegando que cobririam os gastos com as diligências.

Os sucessivos abusos vinham de longa data e levaram a Inquisição, ainda em 1693, a limitar os privilégios dos familiares a certo número de oficiais. Mas como demonstra a historiadora, as medidas não inibiram a procura pelo cargo, tampouco foram suficientes para desencorajar impostores. Se o controle total sobre a milícia inquisitorial era difícil, a capacidade de coação dos familiares e as prisões que executavam, alimentando os cárceres inquisitoriais, faziam desses personagens peças fundamentais para o funcionamento do braço inquisitorial na Colônia.

Agentes da fé oferece, por tudo que se disse, uma contribuição valiosa para a historiografia sobre a Inquisição. Concebido na interseção entre a história social e a história institucional, a obra interessa também aos demais estudiosos do período colonial, descortinando aspectos importantes da burguesia mercantil. A edição tardia desse estudo implicou, no entanto, o descompasso entre o balanço historiográfico elaborado por Calainho e as investigações mais recentes sobre o tema, como a do americano James E. Wadsworth (2006) a respeito dos 'familiares do número', grupo de oficiais da milícia inquisitorial agraciado com privilégios após o decreto de d. Pedro II, e o estudo sobre os familiares da irmandade de São Jorge de Lisboa que realizamos em 2002 (Santos, 2005).

As ausências não comprometem, entretanto, a qualidade de um livro pioneiro, bem escrito e citadíssimo pelos especialistas. Agentes da 
fé chega em boa hora, saldando uma dívida antiga com seus leitores e com a autora, cujas pesquisas sobre o tribunal inquisitorial têm sempre muito a acrescentar.

\section{REFERÊNCIAS BIBLIOGRÁFICAS}

Calainho, Daniela Buono Metrópole das mandingas: religiosidade negra e Inquisição portuguesa no 2000 Antigo Regime. Tese (Doutorado em História) - Universidade Federal Fluminense, Niterói.

Lima, Lana Lage da Gama A confissão pelo avesso: o crime de solicitação no Brasil colonial. 1990 Tese (Doutorado) - Universidade de São Paulo, São Paulo.

Mott, Luiz 1993

Rosa Egipcíaca: uma santa africana no Brasil. Rio de Janeiro: Bertrand.

Novinsky, Anita 1972

Salvador, José Gonçalves 1969

Santos, Georgina Silva 2005

Cristãos-novos na Bahia. São Paulo: Perspectiva.

Siqueira, Sônia de 1978

Souza, Laura de Mello e 1986

Vainfas, Ronaldo. 1989

Wadsworth, James E. 2006

Cristãos-novos, jesuítas e Inquisição. São Paulo: Edusp.

Ofício e sangue: a irmandade de São Jorge e a Inquisição na Lisboa moderna. Lisboa: Colibri.

A Inquisição portuguesa e a sociedade colonial. São Paulo: Ática.

O diabo e a Terra de Santa Cruz. São Paulo: Companhia das Letras.

Trópico dos pecados. Rio de Janeiro: Campus.

Os familiares do número e o problema dos privilégios. In: Vainfas, Ronaldo; Fleiter, Bruno; Lage, Lana (Org.). A Inquisição em xeque: temas, controvérsias e estudos de caso. Rio de Janeiro: Ed. Uerj.

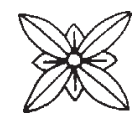

